Voix et Images

voixetimages

\title{
Télévision. La Dernière Chronique
}

\section{Jean-Pierre Lefebvre}

Volume 3, numéro 1, septembre 1977

Nicole Brossard

URI : https://id.erudit.org/iderudit/200100ar

DOI : https://doi.org/10.7202/200100ar

Aller au sommaire du numéro

Éditeur(s)

Les Presses de l'Université du Québec

ISSN

0318-9201 (imprimé)

1705-933X (numérique)

Découvrir la revue

Citer cet article

Lefebvre, J.-P. (1977). Télévision. La Dernière Chronique. Voix et Images, 3(1), 160-162. https://doi.org/10.7202/200100ar d'utilisation que vous pouvez consulter en ligne.

https://apropos.erudit.org/fr/usagers/politique-dutilisation/ 


\section{Télévision}

\section{La Dernière Chronique}

Je me suis fait prendre, au cours des années, à l'objectivation de ma subjectivité. Encore des mots savants dans une revue savante... Je veux simplement dire que si, tel un papillon de nuit qui va se coller à la première lumière allumée, j'ai pu, depuis une vingtaine d'années, passer plus d'une soirée devant le petit écran, étant relativement moins éphémère que le dit papillon j'ai appris à contrôler mes erreurs de navigation et à faire une nette distinction entre la lampe catodique et le soleil. En un mot: l'exercice systématique de mes muscles de réflexion et d'analyse a engendré dans mon espace mental et émotionnel les anticorps télévisuels. “T'sé j'veux dire? La tévé j'la prends pu pantoute, a me rend malade!»

Voilà qui n'est pas très sérieux. Voilà même que, abandonnant le combat de l'analyse, je fais preuve, assurément, d'un manque de respon- 
sabilité. Espérons alors que l'analyse de mon irresponsabilité sera de quelque utilité!

J'abuse ici du je. Pour la raison bien simple que la télévision ne parle jamais au je et à je, et que conséquemment elle élimine toute possibilité de créer le NOUS. II n'y a que des ils et des elles à la télévision. (Deux exceptions de taille, cependant: la série les Exclus - bien que criminellement massacrée par la publicité -, et le Son des Français d'Amérique. Je pourrais également citer Carcajou et le péril blanc.)

La télévision c'est "les autres». En commençant par les romanssavons qui, en principe, parlent d'un ici mais tel un ailleurs, tel un no man's land culturel, social, sexuel, psychologique et politique. Une semblable aseptisation nous transforme en ils et elles parfaitement débranchés de la quotidienneté.

La télévision c'est "les autres", ceux des informations qui ne parlent jamais de je ou de nous en relation avec ici, mais essentiellement en état de rupture: accidents, meurtres, cataclysmes, conflits, guerres, ainsi de suite...

La télévision c'est encore davantage «les autres» de la publicité, autres qui eux s'intègrent au dénominateur commun de la consommation, de la beauté, du rêve... de l'aseptisation. Dans la publicité, on ne flatte le je et le nous, et de la plus malhonnête manière, que pour les détruire, que pour les assimiler aux ils des identiques, du troupeau.

La télévision c'est «les autres» des mythes de notre civilisation: policiers, artistes, hommes d'État, voleurs-gentlemen. Nous, simples humains robotisés dans et par le travail dont les profits nourrissent les mythes qui nous éloignent de nous, nous ne sommes - devenons - que de purs voyeurs, de purs impuissants chroniques. (Radio-Canada, par exemple, passait en reprise cet été, le lundi, à huit heures: le Grand Amour de Balzac, à neuf heures: Paul Gaugin. Ces deux séries françaises sont des chefs-d'cuvre de misogynie en plus d'exalter de manière intoxiquante l'individualisme égoïste de l'artiste «en marge» de sa société. Elles font reculer chez le je et le nous la nécessité de créer le nous collectif, elles découragent l'action du je et du nous par ailleurs matraqués de tabous qu'on sublimise pour des raisons de rentabilité.)

Je ne prendrai pas (plus) la peine de hacher menu les exemples, d'étudier les recoins de la programmation, de séparer le bon grain de l'ivraie: le SYSTEME GLOBAL de production-consommation de la télévision a le cancer, inutile de vouloir sauver quelques vertèbres, un orteil et «l'âme». Inutile de rafistoler le système. La télé-passivité est une menace tout aussi grande que la radio-activité. La corrosion de l'Histoire fera le reste.

Sauf que je-nous, d'ici et d'ailleurs, avons encore la possibilité de fermer le petit écran et de je-nous projeter dans notre vraie vie au lieu 
de laisser celle des ils, jécistes du gouvernement et boy-scouts de la libre entreprise, nous rendre insatisfaits de ce que nous ne sommes pas: nos rêves.

Jean-Pierre Lefebvre 